\title{
Hybrid treatment of arteriovenous fistula between popliteal vessels
}

\section{Tratamento híbrido para fístula arteriovenosa entre vasos poplíteos}

Adenauer Marinho de Oliveira Góes Junior 1,2, Salim Abdon Haber Jeha', Reinaldo Sérgio Monteiro Franco ${ }^{1,2}$

\begin{abstract}
The authors describe treatment of a patient who presented an arteriovenous fistula between the popliteal vessels more than 20 years after a gunshot wound. The patient underwent endovascular treatment using Viabahn (Gore ${ }^{\circledR}$ ) stent grafts, but, because of the large disparity in popliteal artery diameters proximal and distal of the fistula, the endovascular treatment was unsuccessful. The superficial femoral artery was then banded around the stent graft that was deployed previously. This improvised strategy allowed an open surgical approach to be performed far from the fistula site, reducing the risks of operating in a region with anatomic distortions and significant enlargement of the surrounding venous structures, which would certainly have increased the likelihood of iatrogenic injuries.
\end{abstract}

Keywords: arteriovenous fistula; surgery; popliteal artery; popliteal vein; endovascular procedure; vascular system injuries.

\section{Resumo}

Os autores descrevem o tratamento de um paciente portador de fístula arteriovenosa entre vasos poplíteos com mais de 20 anos de evolução, após ferimento por projétil de arma de fogo. O paciente foi submetido a tratamento endovascular pelo implante de stents revestidos Viabahn $\left(\right.$ Gore $\left.^{\circledR}\right)$, porém o mesmo não foi bem sucedido devido à diferença de diâmetro entre a artéria poplítea proximal e a distal à fístula. A artéria femoral superficial foi submetida à cerclagem com fios de sutura ao redor do stentgraft previamente implantado. Esse recurso de improvisação permitiu uma abordagem distante do sítio da fístula, diminuindo os riscos do acesso cirúrgico em uma região com distorções anatômicas e vasos sanguíneos ectasiados, o que certamente acarretaria maior risco de lesões iatrogênicas.

Palavras-chave: fístula arteriovenosa; cirurgia; artéria poplítea; veia poplítea; procedimento endovascular; lesões do sistema vascular.

\footnotetext{
'Universidade Federal do Pará - UFPA, Belém, PA, Brazil.

${ }^{2}$ Centro Universitário do Estado do Pará - CESUPA, School of Medicine, Belém, PA, Brazil.

Financial support: None.

Conflicts of interest: No conflicts of interest declared concerning the publication of this article.

Submitted: 03.05.14. Accepted: 06.18.14.
} 


\section{INTRODUCTION}

Formation of arteriovenous fistulas (AVF) is one complication that can result from vascular traumatisms. ${ }^{1-3}$ Clinical presentation and the time interval between suffering the trauma and diagnosis of AVF can vary greatly; in some cases detection occurs decades after the injury. ${ }^{3,4}$

A range of different surgical techniques are commonly used to treat traumatic AVFs in the extremities, including ligature, disconnections with direct repair and resection of the fistula with reconstruction of vessels. However, recent reports show that endovascular techniques are becoming ever more routine. The main advantages are minimal bleeding, the possibility of operating under local anesthesia, ${ }^{1}$ lower incidence of surgical wound infections and shorter length of hospital stay. ${ }^{5}$

If traumatic AVFs of the lower limbs are not treated early on, they can manifest years after the trauma as venous hypertension, characterized by edema of the involved limb, ochre dermatitis and ulceration; claudication and symptoms of congestive heart failure can also occur. ${ }^{3,6}$

\section{PART I - CASE DESCRIPTION}

The patient was a 44-year old male who had suffered a firearm projectile wound in the left thigh 21 years previously.

The patient was suffering from varicose veins, edema and pain in the left lower limb (Figure 1). No distal pulses were palpable in the affected limb and murmur and thrill were detected in the topography of the left popliteal vessels.

Digital subtraction angiography showed a voluminous AVF linking the popliteal vessels and a pseudoaneurysm of the popliteal artery adjacent to the AVF, all located above the knee joint midline (Figure 2). The patient had been attempting to access definitive treatment on the Brazilian National Health Service (SUS - Sistema Único de Saúde) for many years.

\section{PART II - WHAT WAS DONE?}

Endovascular treatment was prescribed. Two Viabahn $\left(\right.$ Gore $\left.^{\circledR}\right)$ stent grafts were available with the following dimensions: $6 \mathrm{~mm} \times 5 \mathrm{~cm}$ and $7 \mathrm{~mm}$ $\times 15 \mathrm{~cm}$. The procedure was conducted under local anesthesia. There was a large difference between the diameter of the popliteal artery proximal to the AVF and its diameter immediately distal from the AVF and so the decision was taken to employ the $6 \mathrm{~mm} \times 5 \mathrm{~cm}$

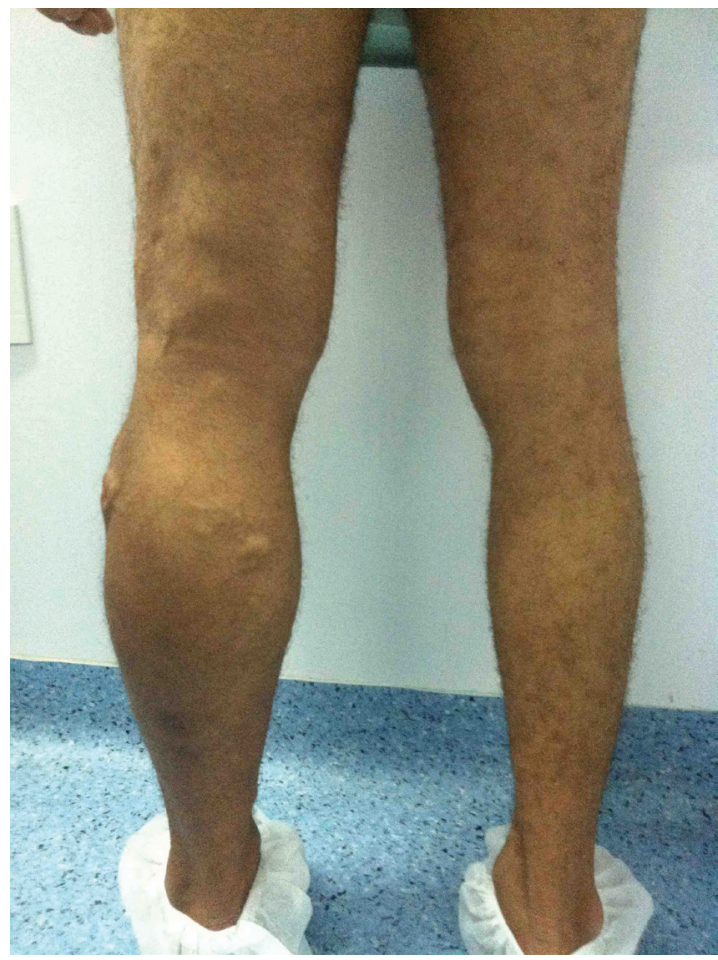

Figure 1. Edema and large caliber varicose veins in the left lower limb.

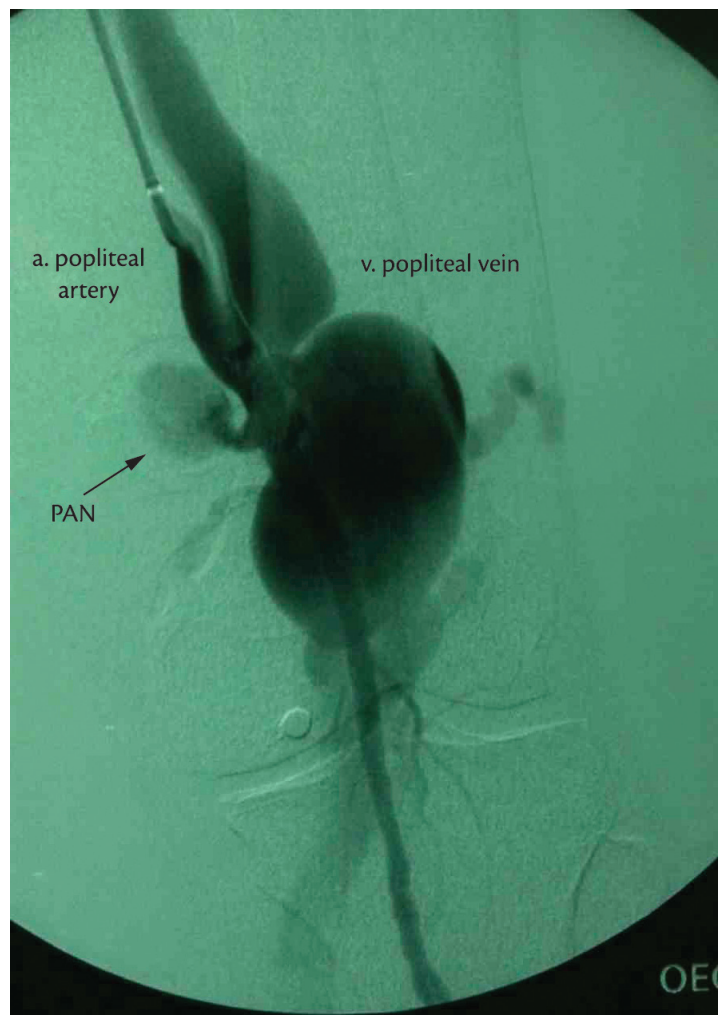

Figure 2. Angiography showing the AVF, a voluminous saccular dilation of the popliteal vein, the discrepancy in popliteal artery caliber proximal to and distal from the AVF, and the pseudoaneurysm (PAN). 
stent. A control angiography showed that the stent was a good fit to the diameter of the popliteal artery distal of the AVF, but that blood continued to flow through the AVF and into the pseudoaneurysm because of leakage at the proximal end of the stent graft, where the diameter was too small for the artery.

The $7 \mathrm{~mm} \times 15 \mathrm{~cm}$ Viabahn $\left(\right.$ Gore $\left.^{\circledR}\right)$ stent graft was then released inside the stent that had already been implanted, with an overlap of about $4 \mathrm{~cm}$. A further control angiography showed that there was still contrast leakage at the proximal 'neck', maintaining the flow to the pseudoaneurysm and through the AVF (Figure 3).

At this point, the procedure was suspended and the puncture site was compressed manually for around 20 minutes. Heparinization reversal was not attempted. Physical examination showed that the intensities of murmur and thrill in the topography of the AVF had reduced considerably and the pedial pulse, which had not been palpable before the procedure, was now present.

The patient was kept on anticoagulation to avoid arterial thrombosis while the possibilities for intervention were assessed. The patient was transported to the operating theater around 12 hours after termination of the endovascular procedure.

The decision was taken to manage the superficial femoral artery surgically, since it was elongated, tortuous and ectatic. It was possible to identify, by transparency, the proximal limit of the stent graft inside the vessel (Figure 4). Two bands were created with vicry $l^{\circledR} 0$ suture thread, about $2 \mathrm{~cm}$ apart, close below the proximal limit of the stent (Figure 5). Angiography by direct arterial puncture proximal to the stent showed that contrast leakage had been stemmed by the banding and no opacification of the pseudoaneurysm of the AVF was visible (Figure 6).

\section{DISCUSSION}

In cases of late treatment of traumatic AVFs, accentuated dilation of venous structures and distorted local anatomy can make surgical access problematic. ${ }^{1,3,6,7}$ Ectatic veins exhibit high flow rate and a relatively thin wall, meaning that a small perforation can provoke a voluminous intraoperative hemorrhage. ${ }^{1,7}$ In the case described here, endovascular treatment had been chosen to avoid the risk of iatrogenic injuries and bleeding associated with direct surgical manipulation of the AVF.

Endovascular treatments for AVFs and pseudoaneurysms that have been described include implantation of covered stents, ${ }^{6-8}$ embolization with coils $^{6,8}$ and use of Amplatzer vascular plugs. ${ }^{1}$
The unsatisfactory technical result of covered stent placement in the case described here was because of the fact that its diameter was too small for the caliber of the popliteal artery proximal of the AVF.

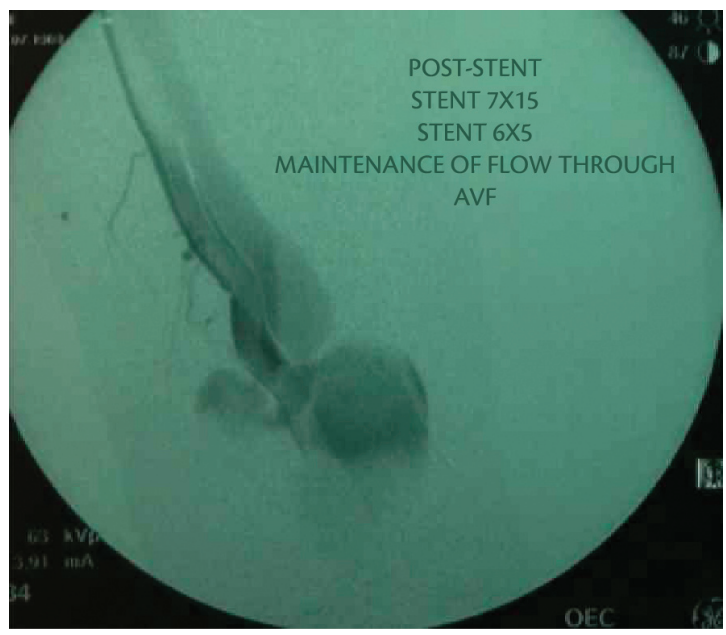

Figure 3. Angiography showing that flow through the AVF and into the pseudoaneurysm continued even after placement of the stents.

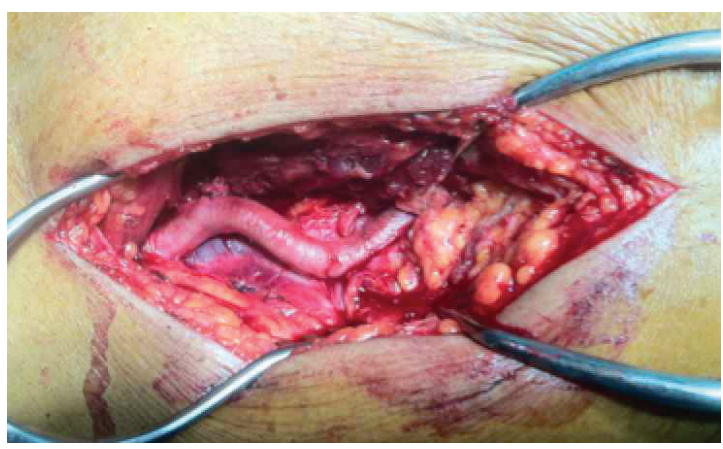

Figure 4. View of ectatic and tortuous superficial femoral artery, showing, by transparency, the stent placed inside the lumen.

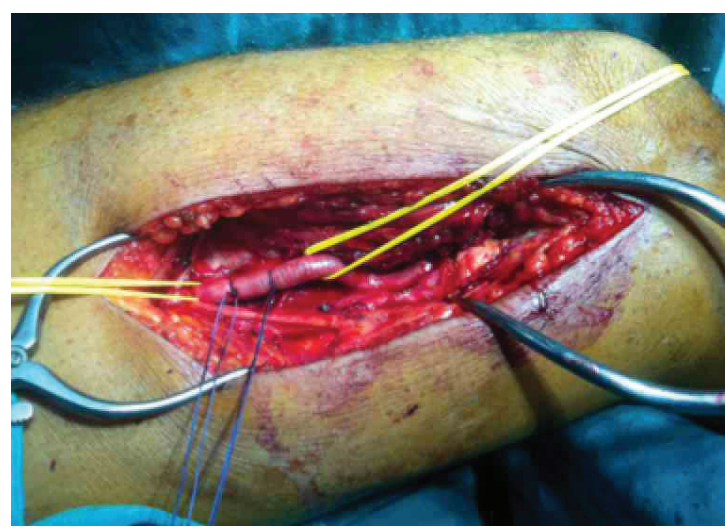

Figure 5. Superficial femoral artery. Banding with suture thread around the stent implanted previously. 


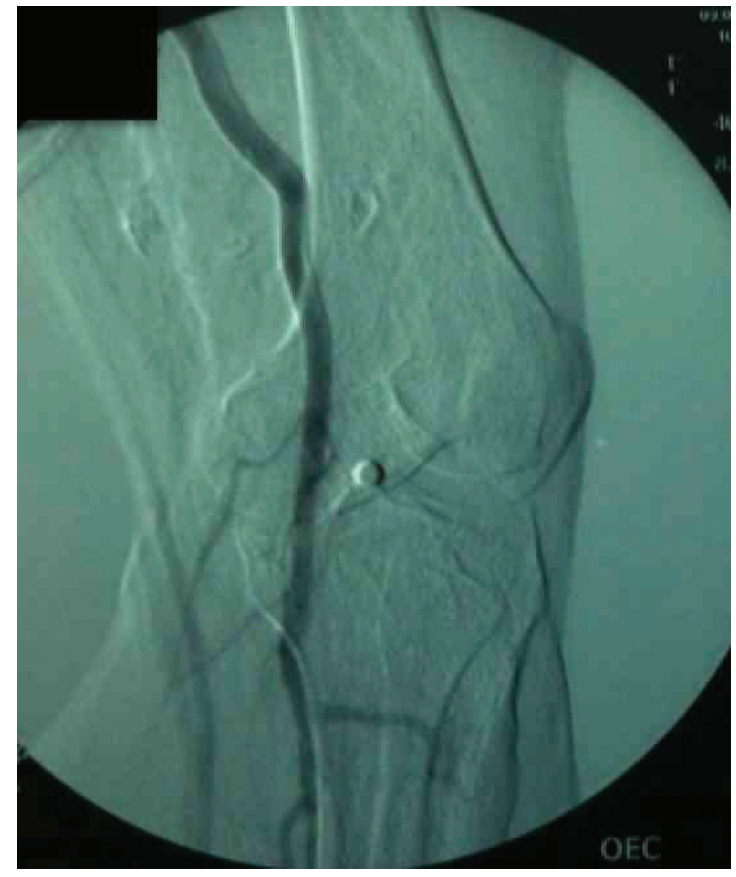

Figure 6. Intraoperative angiography after completion of banding, showing no opacification of the pseudoaneurysm or of the AVF.

Arterial dilation proximal to AVFs was described by Hunter as early as $1753^{\circ}$ and is well-documented in the literature. ${ }^{3,10}$ This dilation can lead to formation of true aneurysms. Although less common, arteriomegaly can continue to develop even after occlusion of the AVF. ${ }^{3,10}$ There is more than one theory attempting to explain arterial dilation proximal of the AVF, one of which is based on intensification of shear forces on the endothelium, secondary to localized increase in vascular flow., ${ }^{3,10}$ According to this theory, there is an increase in production of endothelium-derived relaxing factor, which causes vasodilation by acting on the smooth musculature of the artery. ${ }^{10}$ This theory explains why the arterial branches and the artery distal of the AVF are unaffected by arteriomegaly, ${ }^{10}$ but it cannot explain why the dilation should continue to develop after occlusion of the AVF. ${ }^{3,10}$

An alternative theory is that the chronic increase in arterial flow proximal of the AVF increases the vessel diameter, leading to rupture of elastic fibers. This destruction of the elastic fibers in the artery wall may be linked to progression of arteriomegaly even after occlusion of the AVF. ${ }^{10}$ The phenomenon would be aggravated by changes to local flow hemodynamics. Before occlusion of the AVF, the arterial walls are subject to low peripheral vascular resistance from the aorta to the AVF. After occlusion of the AVF, the increased peripheral resistance in combination with histological changes to the artery wall may explain why arteriomegaly continues to develop. ${ }^{10}$

In the case described here, arteriomegaly proximal of the AVF caused a large discrepancy between the caliber of the popliteal artery proximal of the AVF and its caliber distal to the AVF, making it unlikely that a straight covered stent could be fitted adequately to two such disparate diameters.

Bearing in mind that there were only two stents available and due to the fact that angiography had shown that the popliteal artery distal of the AVF had a smaller than normal diameter, the initial attempt was made by releasing the $6 \mathrm{~mm} \times 5 \mathrm{~cm}$ stent, on the basis that it was believed that a larger diameter stent would not be able to expand sufficiently inside the popliteal artery distal of the injury.

The $7 \mathrm{~mm} \times 15 \mathrm{~cm}$ Viabahn $\left(\right.$ Gore $\left.^{\circledR}\right)$ stent was then placed inside the first stent, with the objective of extending the region covered by the stent to a segment of the artery with a normal diameter. After this maneuver, a portion of the superficial femoral artery distant from the neck of the AVF and from the pseudoaneurysm was covered by the stent. However, a further control angiography showed that contrast continued to leak from the proximal 'neck', maintaining flow into the pseudoaneurysm and through the AVF, because the stent's $7 \mathrm{~mm}$ diameter was not large enough to occupy the entire lumen of the superficial femoral artery.

The technique of arterial banding has been described previously as an ancillary maneuver for treatment of endoleaks after endovascular treatment of abdominal aorta aneurysms. ${ }^{11,12}$ However, we were unable to find any reports of arterial banding around a covered stent to treat a peripheral AVF in a review of the literature and our use of this strategy in this context appears to be novel.

This improvised strategy combined with placement of a long covered stent made it possible to conduct an approach far from the AVF site, reducing the risks of surgical access in a region with anatomic distortions and ectatic blood vessels, which would certainly have increased the likelihood of iatrogenic injuries.

\section{REFERENCES}

1. Park YN, Kim JH, Choi ST, et al. Endovascular therapy of a traumatic chronic popliteal arteriovenous fistula using an AMPLATZER vascular plug.J Vasc Interv Radiol. 2010;21(11):177982. http://dx.doi.org/10.1016/j.jvir.2010.07.023. PMid:20934885

2. Huang W, Villavicencio JL, Rich NM. Delayed treatment and late complications of a traumatic arteriovenous fistula. J Vasc Surg. 
2005;41(4):715-7. http://dx.doi.org/10.1016/j.jvs.2005.01.049. PMid:15874939

3. Chaudry M, Flinn WR, Kim K, Neschis DG. Traumatic arteriovenous fistula 52 years after injury. J Vasc Surg. 2010;51(5):1265-7. http:// dx.doi.org/10.1016/j.jvs.2009.11.080. PMid:20299180

4. O'Brien GC, Murphy C, Martin Z, et al. Hybrid management of a spontaneous ilio-iliac arteriovenous fistula: a case report. J Med Case Reports. 2011;5(1):401-3. http://www.jmedicalcasereports. com/content/5/1/401. http://dx.doi.org/10.1186/1752-1947-5401. PMid:21859469

5. Alserr AH, Antonopoulos CN, Papapetrou A, Kakisis JD, Brountzos E, Liapis CD. Endovascular repair of popliteal artery pseudoaneurysm with arteriovenous fistula after knee arthroscopy: case report and literature review. Vasc Endovascular Surg. 2014;48(2):166-70. http://dx.doi.org/10.1177/1538574413512379. PMid:24302163.

6. Nagpal K, Ahmed K, Cuschieri R. Diagnosis and management of acute traumatic arteriovenous fistula. Int J Angiol. 2008;17(4):2146. http://dx.doi.org/10.1055/s-0031-1278313. PMid:22477453

7. Medeiros CAF, Hatsumura TC, Gusmão DR, Freire LMD, Rocha EF, Guillaumon AT. Tratamento endovascular do trauma arterial dos membros. J Vasc Bras. 2008;7(1):56-61. http://dx.doi.org/10.1590/ S1677-54492008000100010.

8. Marine L, Sarac TP. Hybrid stent-graft repair of an iatrogenic complex proximal right common carotid artery injury. Ann Vasc Surg. 2012;26(4):574.e1-7. http://dx.doi.org/10.1016/j. avsg.2011.08.023. PMid:22445243

9. Hunter W. The history of an aneurysm of the aorta with some remarks on aneurysms in general. Trans Med Obstet Soc Phys. 1757; 1:323.

10. Hartung O, Garcia S, Alimi YS, Juhan C. Extensive arterial aneurysm developing after surgical closure of long-standing post-traumatic popliteal arteriovenous fistula. J Vasc Surg. 2004;39(4):889-92. http://dx.doi.org/10.1016/j.jvs.2003.10.059. PMid:15071459

11. Becquemin J-P, Kelley L, Zubilewicz T, Desgranges P, Lapeyre M, Kobeiter $\mathrm{H}$. Outcomes of secondary interventions after abdominal aortic aneurysm endovascular repair. J Vasc Surg. 2004;39(2):298305. http://dx.doi.org/10.1016/j.jvs.2003.09.043. PMid:14743128
12. Hobo R, Buth J, and the EUROSTAR collaborators. Secondary interventions following endovascular abdominal aortic aneurysm repair using current endografts. A EUROSTAR report. J Vasc Surg. 2006;43(5):896-902. http://dx.doi.org/10.1016/j.jvs.2006.01.010. PMid:16678679

Correspondence Adenauer Marinho de Oliveira Góes Junior Rua Domingos Marreiros, 307/802 CEP 66055-210 - Belém (PA), Brazi

E-mail: adenauer-junior@ibest.com.br; adenauerjunior@gmail.com

Author information AMOG - Vascular surgeon; Professor of Medical Skills (Semiology), School of Medicine, Universidade Federal do Pará (UFPA); Professor, Surgical Practice Internship (Vascular Surgery), School of Medicine, Centro Universitário do Estado do Pará (CESUPA); MSc from the Graduate Program in Interdisciplinary Surgical Sciences, Universidade Federal de São Paulo (UNIFESP)

SAHJ - Vascular surgeon; Professor of Adult General Medicine (Angiology and Vascular Surgery), School of Medicine, Universidade Federal do Pará (UFPA)

RSMF - Vascular surgeon; Professor of Medical Skills (Surgical Techniques), School of Medicine, Universidade Federal do Pará (UFPA); Professor, Surgical Practice Internship (Vascular Surgery), School of Medicine, Centro Universitário do Estado do Pará (CESUPA)

Author contributions Conception and design: AMOG, SAH Analysis and interpretation: AMOG, SAH Data collection: $\mathrm{AMOG}$ Writing the article: $A M O G, S A H$ Critical revision of the article: AMOG, RSMF Final approval of the article*: AMOG, SAHJ, RSMF Statistical analysis: N/A Overall responsibility: $\mathrm{AMOC}$ Obtained funding: None.

*All authors have read and approved of the final version of the article submitted to I Vasc Bras. 